\title{
Differential Effects of Valproic Acid on Immobility Responses and Locomotor Activity in Female and Male Rats
}

\author{
Oscar Morales-Dionisio', Fidel de la Cruz¹, Margarita Franco-Colín1, Oriana Hidalgo-Alegría1, \\ Gonzalo Flores ${ }^{2}$, José Luna-Muñoz ${ }^{3}$, Linda Garcés-Ramírez ${ }^{1}$ \\ ${ }^{1}$ Departamento de Fisiología, Escuela Nacional de Ciencias Biológicas, Instituto Politécnico Nacional, Ciudad de México, México \\ ${ }^{2}$ Laboratorio de Neuropsiquiatría, Instituto de Fisiología, Benemérita Universidad Autónoma de Puebla, Puebla, México \\ ${ }^{3}$ Departamento de Fisiología, Biofísica y Neurociencias, Centro de Investigación de Estudios Avanzados del Instituto \\ Politécnico Nacional, Ciudad de México, México \\ Email: LindaGarcés-Ramírezadnil_gr@yahoo.com.mx
}

How to cite this paper: Morales-Dionisio, O., de la Cruz, F., Franco-Colín, M., Hidalgo-Alegría, O., Flores, G., Luna-Muñoz, J. and Garcés-Ramírez, L. (2017) Differential Effects of Valproic Acid on Immobility Responses and Locomotor Activity in Female and Male Rats. Pharmacology \& Pharmacy, 8, 339-353.

https://doi.org/10.4236/pp.2017.810025

Received: September 26, 2017

Accepted: October 21, 2017

Published: October 24, 2017

Copyright $(0) 2017$ by authors and Scientific Research Publishing Inc. This work is licensed under the Creative Commons Attribution International License (CC BY 4.0).

http://creativecommons.org/licenses/by/4.0/

\section{Open Access}

\begin{abstract}
Valproic acid (VPA) is used in the treatment of epilepsy and behavioral disorders. However, the exposure to VPA during pregnancy increases the risk of having offspring with autism spectrum disorder (ASD). Reports indicate that men are more likely to suffer ASD than women who were exposed to VPA prenatally. Few studies have related the sex differences and behavioral changes in the ASD rat model. Our aim was to determinate whether male and female Wistar rats whose mothers were exposed to either VPA $(600 \mathrm{mg} / \mathrm{kg}$; animal model for ASD) or saline (0.9\%) i.p. at 12.5 day of gestation, have different effects on immobility induce by clamping (IC), dorsal immobility (DI), catalepsy, locomotor activity, stereotypes, and analgesia (tail flick). For this purpose, we made four groups $(n=8)$. Group: A) saline male rats, B) saline female rats, C) VPA male rats and D) VPA female rats. At 35 (prepubertal age), 56 (postpubertal age) and 180 days, we tested the behaviors previously mentioned. Finding that VPA has the same effect on IC, catalepsy, and analgesia in male and female rats, the time of these tests was increased. However, VPA only has an effect on DI in males but not in female rats. On the contrary, there is hyperactivity and an increase of stereotypes in female but not in male rats. Thereby, VPA has an effect on the three immobility responses tested (IC, DI and catalepsy), locomotor activity and analgesia but in a differential way on DI, stereotypes and locomotor activity between male and female rats.
\end{abstract}

\section{Keywords}

Autism, Immobility Responses, Animal Model for ASD,

Locomotor Activity, Valproic Acid 


\section{Introduction}

Valproic Acid (VPA) is used as anticonvulsant drug due to its efficiency treating seizures, and it is also prescribed as a mood stabilizer. However, the use of VPA during the pregnancy, as well as other antiepileptic drugs, is associated with teratogenic alterations and congenital malformations [1]. Even if VPA is administered with another anticonvulsant drug, it can induce effects more pervasive than that it induces itself [2]. VPA has been also proposed as an important factor in the etiology of autism. Some reports show that mothers who were administered with VPA when they were pregnant had children with similar symptoms to children with autism [3] [4] [5].

The autistic spectrum disorder (ASD) is a pervasive developmental disorder (PDD). According to the DSM-V 5th edition [6], the diagnostic is mainly based on: 1) persistent deficits in social interaction, 2) presence of repetitive behaviors such as stereotypical movements, 3 ) the symptoms that must be present in early developmental stages, though symptoms may manifest in later stages, 4) impairment in social functioning, 5) intellectual disability and social communication abilities that are lower than expected for general development level, which are not explained by intellectual disabilities.

Reports show that some autistic persons, as well as some autistic animal models have genetic alterations [7] [8], suggesting that autism has a main genetic origin, although it can be a polygenetic disorder [9] founding deletions and other changes in chromosomes [10] [11] [12]. About genetics, autism is diagnosed more frequently in men than women, at a ratio of 4:1 [13] [14]. In animal models, sex differences in synaptic connectivity have been described which might lead to differences in prenatal VPA exposure. It seems that females are less vulnerable to exhibit autistic symptoms than males, which could be due to the innate mechanisms of protection that are present in females [15] [16]. However, changes have also been found in the brains of female autistic patients [17].

Animals prenatally exposed to VPA show similar effects to humans with autism [18]. Some of these changes are: hyperconnectivity and hyperplasticity in the frontal cortex [19], a decrease in the number and size of the amygdala neurons [20] [21], a reduction in the number of Purkinje cells in cerebellum [22] [23], an increase in the volume of caudate one [24], and a series of changes in the hippocampus [25] [26] such as reduction in the size of CA4 cells and the dendritic branching of the CA1 and CA4 cells [27]. Besides, some changes in neurotransmission have been found, such as delay in the maturation of serotonergic neurons [28], an increase of the serotonin neurotransmission in the hippocampus, as well as an increase in dopaminergic neurotransmission in the frontal cortex [29]. A neuroprotective VPA effect on dopaminergic neurons in the midbrain has also been found [30]. An increase in NMDA receptors [31], a reduction in enkephalins [32], and alterations in the endocannabinoid system in the hippocampus and the cortex have also been reported [33].

Behavioral changes induced by VPA were found during the early postnatal life 
of animals, among which are: an increase in stereotypic time and number of stereotypes, low sensitivity to painful stimuli, and high sensitivity to non-painful stimuli [34] [35] [36]. These animals also have less social interaction.

As we mentioned before, the ASD is characterized by a deficiency in social interaction, verbal and nonverbal impairments. Within these alterations, there are lack of ocular contact, facial expressions, and corporal gestures, as well as cognitive impairments and sensorimotor deficits [37]. A person with ASD also shows stereotypical behaviors. These individuals can be also vulnerable to catatonia [38] [39] [40], but also have freezing and slow movements [41] that can reflect immobility.

Immobility responses are characterized by a lack of response to external stimuli. These kinds of behaviors are presented in a great variety of species and they are shown in a wide spectrum of circumstances, from transport offspring to escape from predators [42]. This response can also occur in neurodevelopment diseases, as schizophrenia [43]. Behavioral changes have been described in animal models with neurodevelopmental diseases, such as immobility responses, locomotor activity and a diminished response to pain. Thus, the purpose of this study was to investigate possible links among these behaviors in a model of autism by exposure to VPA. Furthermore, we wanted to compare these responses between male and female rats.

\section{Methods}

Wistar rats were housed in a temperature- and humidity-controlled environment on $12 \mathrm{~h}$ light/dark cycle, with free access to food and water. The progeny exposed to either VPA or saline in utero was obtained letting the progenitors rats mate for two hours (period of time enough to get pregnant the rat). Pregnancy was determined by the presence of a vaginal plug, taking this as the first day of gestation. At day 12.5 of gestation, each rat was intraperitoneally injected with saline $(0.9 \%)$ or sodium valproate $(600 \mathrm{mg} / \mathrm{kg})$. Four groups were formed with the offspring of mothers injected with saline or sodium valproate (VPA): male rats exposed to saline $0.9 \%$, female rats exposed to saline $0.9 \%$, male rats exposed to VPA and female rats exposed to VPA (eight rats per litter). The offspring were weaned on postnatal day (PD) 21, and were housed in the same groups formed before. Different behavioral tests as immobility responses, locomotor activity, and analgesia, were measured on PD 35 (prepubertal age; $\mathrm{n}=8$ ), PD 56 (postpubertal age; $n=8$ ) and PD 180 days (adulthood; $n=6$ ). The effect obtained was statistically significant with six adult rats, so was no necessary to use more.

All experimental procedures described in this study are in accordance with the guidelines of the Mexican government (NOM-062-ZOO-1999), which details the technical specifications for production, care, and use of laboratory animals. The internal Bioethics Committee approved this protocol. 


\subsection{Immobility Responses}

The immobility responses were induced in the rats on PD 35, 56 and 180, by the following three methods [44].

\subsubsection{Immobility Induced by Clamping}

Two clamps were applied, one on the ventral neck and the other on the back of the neck; the pressure was sufficient to lift the whole rat with the clamp. Then, the rat was placed on a flat surface on its side. The duration of the response was measured, since the animal was placed on its side, until it recovered its prone position, or for a maximum of $180 \mathrm{~s}$ [44].

\subsubsection{Dorsal Immobility}

The rat was gently grasped by the skin of the dorsal neck and lifted off its feet; preventing any part of the rat from touching any other surface. The duration of the dorsal immobility response was measured once the rat was still (which was instantaneous) until it made escape-like movements or for a maximum of $180 \mathrm{~s}$.

\subsubsection{Cataleptic Clinging}

The rat was placed on two horizontal stainless steel rods ( $2 \mathrm{~mm}$ in diameter, 19 $\mathrm{cm}$ long, mounted $8 \mathrm{~cm}$ (or adjusted to the rat) vertically apart) in a Plexiglas support $(23.5 \times 20.5 \times 12.3 \mathrm{~cm})$. The duration of the response was measured once the rat was still (which was instantaneous) until the rat did not sustain the position or for a maximum of $180 \mathrm{~s}$.

\subsection{Locomotor Activity in an Open-Field (New Environment)}

The rats were taken to the testing room $30 \mathrm{~min}$ previous to the test. Then, each rat was placed in the middle of the open field (black painted wooden box, $60 \mathrm{~cm}$ w $360 \mathrm{~cm} \mathrm{~L} 330 \mathrm{~cm} \mathrm{~h}$ ) [45]. Spontaneous locomotor activity in the new environment was measured with a real-time video image analyzer Videomex-V (Columbus Instruments, Columbus $\mathrm{OH}$ ). It tracked the distance traveled by the rat, as well as the time spent moving, the time spent in a non-ambulatory activity (which includes postural adjustments and stereotyped behaviors such as grooming, rearing, sniffing, etc.), and the resting time. A total of 9 min of activity for each animal was measured for behavioral analysis.

\subsection{Tail Flick Test}

This test measures the sensitivity of the rat to the change of temperature on its tail. This test was done with the Tail-flick Analgesia meter (Columbus Instruments). The rat was restrained in a conical polypropylene tube with an opening through which its tail was exposed. The tail was exposed to a heat lamp (stimulus) and the time was measured from when the stimulus started, until the rat moved or flicked its tail away from the heat. The maximum time allowed for the rat without taking away its tail from the heat lamp was 15 seconds [46]. 


\subsection{Statistical Analysis}

Behavioral test data (immobility responses and locomotor activity) were compared by two-way repeated measures (RM) analysis of variance (ANOVA) test followed by the Student-Newman-Keuls post hoc test comparisons, with VPA exposure treatment, and age as independent factors $(P<0.05$ as statistically significant) and male or female within the subjects factor.

\section{Results}

\subsection{Effect of Prenatal VPA Exposure on Immobility Responses Measured at Different Ages in Male and Female Rats}

In male rats prenatally exposed to VPA (Figure 1(a)), the time of immobility response induced by clamping significantly increased on day 35 vs. control (interaction treatment $\mathrm{X}$ age $\mathrm{F}_{(2,23)}=6.624, P=0.005$; post-hoc test $\left.P<0.001\right)$ but there was not effect at 56 and 180 days. In addition, VPA male rats showed differences at day 35 regarding days 56 and 180 (post-hoc test: day 35 vs. day 56, $P$ $=0.007$; day 35 vs. day $180, P<0.001$; and day 56 vs. day $180, P=0.016$ ). The dorsal immobility response also increased significantly in these rats at 35,56 and 180 days vs. control, having a sustained effect during the three ages studied (Figure $1(\mathrm{c})$ ), (treatment $\mathrm{F}_{(1,14)}=25.889, P<0.001$; post-hoc test: 35 days, $P=$ 0.012; 56 days, $P=0.022$; 180 days, $P=0.002$ ). The duration of catalepsy (Figure $2(a)$ ), increased only on day 35 in VPA male rats vs. control (treatment $F_{(1,14)}=3.476$,

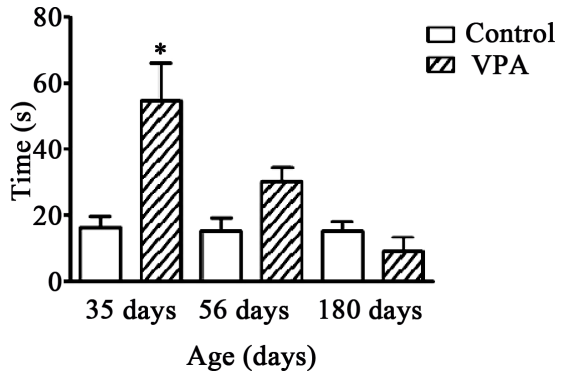

(a)

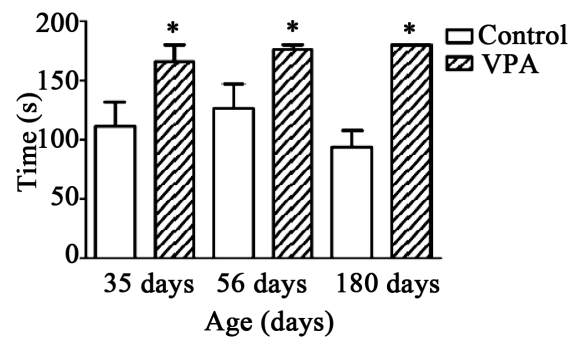

(c)

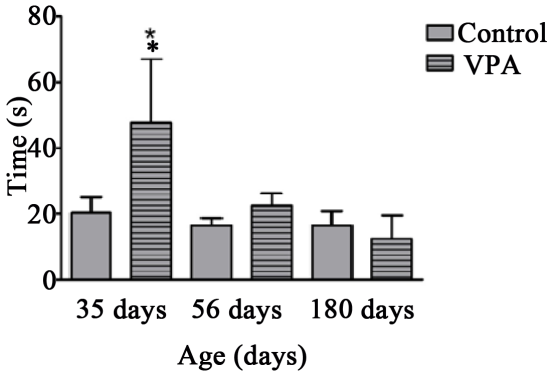

(b)

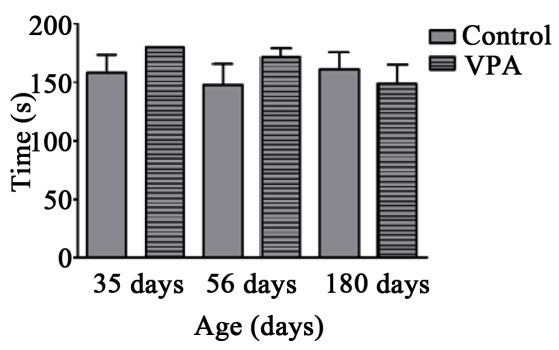

(d)

Figure 1. Time of immobility elicited by clamping (IC) and dorsal immobility (DI) measured at day 35 (prepubertal age), 56 (postpubertal age) and 180 (adulthood) in rats exposed prenatally to valproic acid (VPA). Each bar represents the mean \pm SEM. ${ }^{\star} P<$ 0.05 , VPA vs control. Two-way ANOVA, a post hoc test (Student-Newman-Keuls) was performed for multiple comparisons. (a) IC in male rats; (b) IC in female rats; (c) DI in male rats and (d) DI in male rats. 


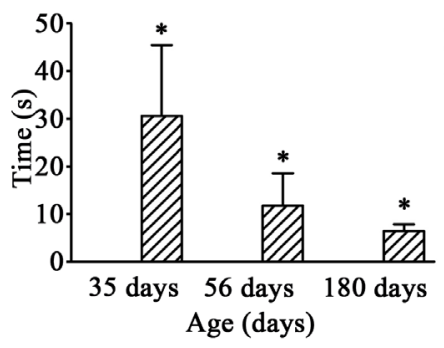

(a)
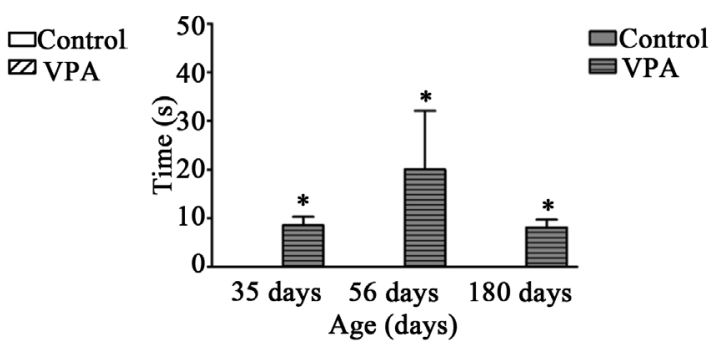

(b)

Figure 2. Time of catalepsy measured at day 35 (prepubertal age), 56 (postpubertal age) and 180 (adulthood) in (a) male and (b) female rats exposed prenatally to valproic acid (VPA). Each bar represents the mean \pm SEM, (bars for controls are not shown because their value is zero) ${ }^{*} P<0.05$, VPA vs control. Two-way ANOVA, a post hoc test (Student-Newman-Keuls) was performed for multiple comparisons.

$P=0.081$; post-hoc test, $P=0.004)$, however, this effect decreased within the ages in VPA (post-hoc test: day 35 vs. day 56, $P=0.057$; day 35 vs. day $180, P=$ 0.017).

Female rats prenatally exposed to VPA also showed an increase of immobility response by clamping (Figure $1(\mathrm{~b})$ ), only on day 35 (treatment $\mathrm{F}_{(1,14)}=1.042, P$ $=0.323$; post -hoc test, $P=0.045)$. Besides, within VPA female rats there were differences between the three ages measured, showing a decrease when the rats got older (age, $\mathrm{F}_{(2,23)}=4.428 ; P=0.044$; post-hoc test: day 35 vs. day $180, P=$ 0.014 ; day 35 vs. day 56, $P=0.030$ ), they had the same behavior as the VPA male rats. In contrast to VPA male rats, VPA treatment in female rats did not have an effect on dorsal immobility duration, Figure 1 (d) (treatment $\mathrm{F}_{(1,14)}=0.968, P=$ 0.340 ). In catalepsy (Figure 2(b)), what was augmented since day 35 and maintained until day 180 (treatment $\mathrm{F}_{(1,14)}=6.822, P=0.019$; post-hoc test, 35 days $P$ $=0.253 ; 56$ day $P=0.011 ; 180$ days $P=0.155)$.

\subsection{Effect of Prenatal VPA Exposure on Locomotor Activity Measured at Different Ages in Male and Female Rats}

VPA male rats had no changes in locomotor activity: distance traveled (Figure $3(\mathrm{a})$ ), ambulatory time (Figure 3(c)), stereotype time (Figure 4(a)) or repose time (Figure $4(\mathrm{c})$ ), at any of the three ages measured (distance traveled, treatment $\mathrm{F}_{(1,14)}=0.777$; time ambulatory, treatment $\mathrm{F}_{(1,14)}=0.441$; stereotypic time, treatment $\mathrm{F}_{(1,14)}=0.0147$; time repose, treatment $\left.\mathrm{F}_{(1,14)}=0.0945\right)$.

On the other hand, VPA female rats showed an increase in locomotor activity (Figure 3(b), Figure 3(d), Figure 4(b), Figure 4(d) respectively): distance traveled (treatment $\mathrm{F}_{(1,14)}=10.362, P=0.005$ ); ambulatory time (treatment $\mathrm{F}_{(1,14)}=$ $8.886, P=0.009$ ) and time of stereotypes (treatment $\mathrm{F}_{(1,14)}=4.878, P=0.043$ ), as a result, the time of repose decreased (treatment $\mathrm{F}_{(1,14)}=6.475, P=0.022$ ). These changes were observed on days 35 and 56 (post hoc test on day 35: distance traveled, $P=0.004$; ambulatory time, $P=0.004$; time of stereotypes, $P=0.051$; time of repose, $P=0.016$; post hoc test on day 56: distance traveled, $P=0.012$; ambulatory time, $P=0.012$; time of stereotypes, $P=0.013$; time of repose, $P=0.009$ ). 


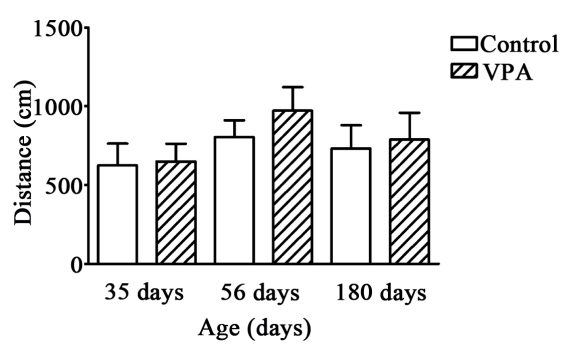

(a)

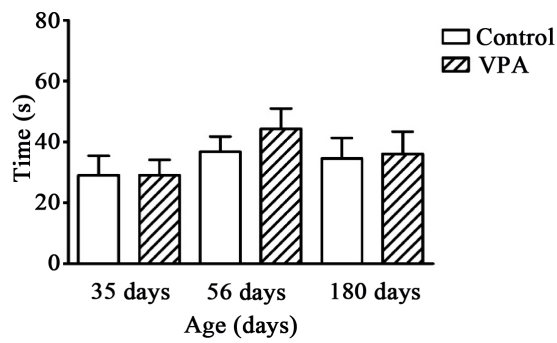

(c)

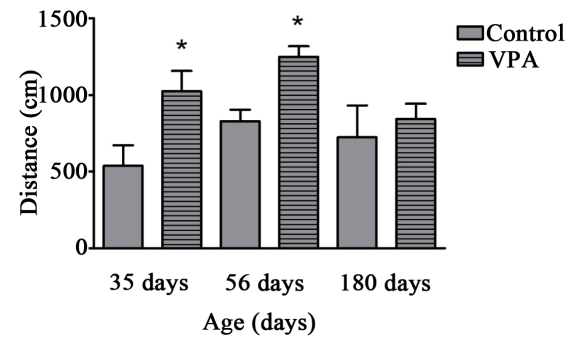

(b)

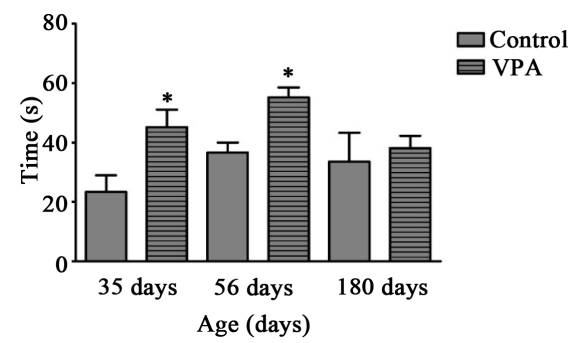

(d)

Figure 3. Distance traveled by (a) male and (b) female rats and ambulatory time of (c) male and (d) female rats exposed prenatally to valproic acid (VPA) at day 35 (prepubertal age), 56 (postpubertal age) and 180 (adulthood). Each bar represents the mean \pm SEM. ${ }^{\star} P$ $<0.05$, vs. control. Two-way ANOVA, post hoc Student-Newm-Keuls.

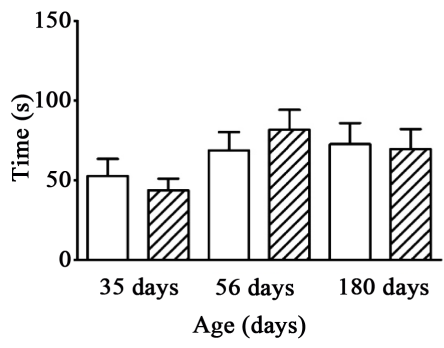

(a)

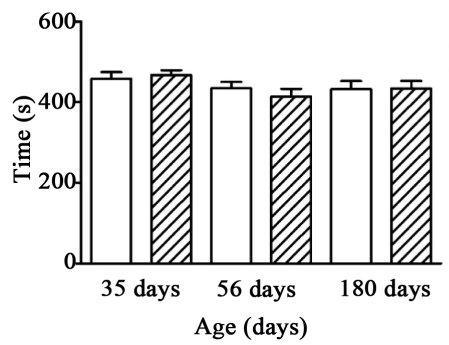

(c)
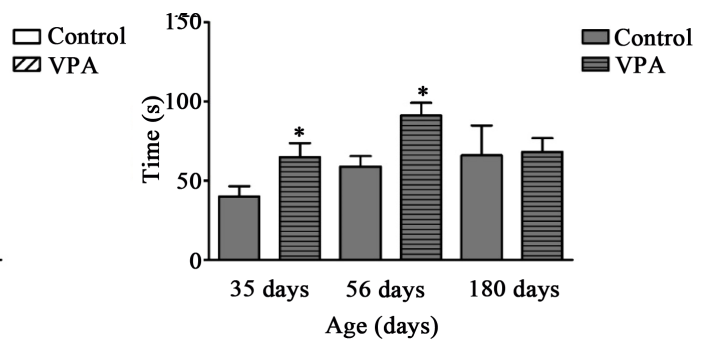

(b)
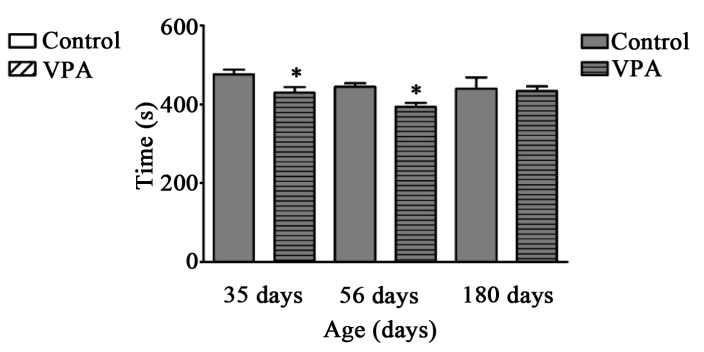

(d)

Figure 4. Time of stereotypies in (a) male and (b) female and time of repose in (c) male and (d) female rats exposed prenatally to valproic acid (VPA) at day 35 (prepubertal age), 56 (postpubertal age) and 180 (adulthood). Each bar represents the mean \pm SEM. ${ }^{\star} P<$ 0.05 , vs. control. Two-way ANOVA, post hoc Student-Newman-Keuls.

Moreover, VPA female rats had significant differences in ambulatory time (age, $\left.\mathrm{F}_{(2,23)}=3.269, P=0.056\right)$, time of stereotypes (age, $\left.\mathrm{F}_{(2,23)}=4.625, P=0.020\right)$ and time of repose (age, $\mathrm{F}_{(2,23)}=4.428, P=0.024$ ), on day 56 (post-hoc. ambulatory time, day 56 vs. day $180, P=0.047$; time of stereotypes, day 56 vs. day $35, P=$ 
0.050 ; day 56 vs. day $180, P=0.041$; time of repose day 180 vs. day $56, P=0.056$; day 35 vs. day $56, P=0.037$ ).

\subsection{Effect of Prenatal VPA Exposure on Tail Flick Test Measured at Different Ages in Male and Female Rats}

In VPA male rats (Figure 5(a)) the time to retract the tail from the heat was augmented (analgesia) (treatment $\mathrm{F}_{(1,14)}=9.572, P=0.007$ ), however, this effect was presented just 35 (post-hoc test $P=0.035$ ) and the 180 days (post-hoc test $P$ $=0.04$ ).

VPA female rats (Figure 5(b)) showed effects only on day 35 (treatment $\mathrm{F}_{(1,14)}$ $=4.299, P=0.053$; post -hoc test, $P=0.012$ ), but there were differences between VPA female rats on the days measured (post-hoc test: day 180 vs. day $35, P=$ 0.021 ; day 180 vs. day $56, P=0.017$; day 56 vs. day $35, P=0.715$ ). Nonetheless, the time to retract the tail was increasing with age in control female rats (age, $\mathrm{F}_{(2,23)}=13.242, P<0.001$; post-hoc test: day 180 vs. $35, P<0.001$; day 180 vs. day $56, P=0.033$; day 56 vs. $35, P=0.021)$.

\section{Discussion}

It has been reported that ASD is 4 to 5 times more frequent in boys than girls. However, recent studies suggest that this rate probably is not real, due to ASD often not being adequately diagnosed in girls/women. Maybe girls/women have different signs and symptoms than boys/men. The majority of the models of ASD in rodents are done in males, because the models in female rodents are very scarce. Based on the above, we decided to evaluate different behaviors in the autism model, administering VPA to pregnant rats. The offspring of these rats was used as a model of autism, because they show signs and features present in people with ASD [47]. In this study, we found that both male and female rats exposed to VPA prenatally exhibit behavioral changes on day 35 (prepubertal age) and these changes were maintained until adulthood (day 180) in some trials. These findings are consistent with clinical reports in which ASD is diagnosed primarily in children. However, we found differences in the behaviors evaluated between male and female rats exposed prenatally to VPA. The immobility

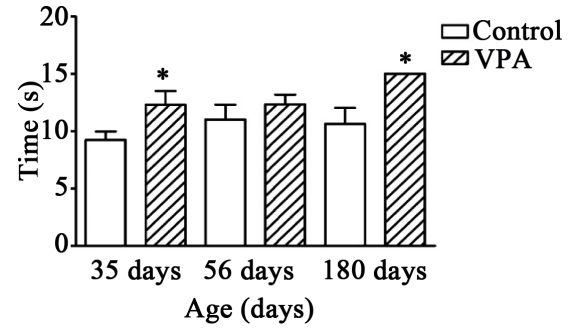

(a)

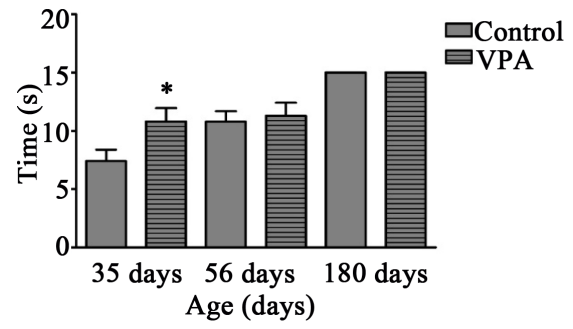

(b)

Figure 5. Analgesia (latency to withdraw the tail from the pain stimulus) in (a) male and (b) female rats exposed prenatally to valproic acid (VPA) at day 35 (prepubertal age), 56 (postpubertal age) and 180 (adulthood). Each bar represents the mean \pm SEM. ${ }^{\star} P<0.05$, vs control. Two-way ANOVA, post hoc Student-Newman-Keuls. 
responses are triggered by a wide range of stimuli [48]. These responses are affected in animal models of neurodevelopmental diseases such as schizophrenia [43] [49]. Besides, disturbances of movements in children could help to diagnose children with ASD [50]. This is the reason why we evaluated three kinds of immobility responses: dorsal immobility (DI); immobility response induced by clamping (IC) and catalepsy. In the IC response, there were no differences between male and female rats exposed to VPA prenatally, both increased their IC duration on day 35 , decreasing significantly with age. In previous works, we have found that the immobility response by clamping is modulated by the dopaminergic, adrenergic system, as well as the hypothalamus-pituitary-adrenal glands [46] [51] [52]. In the neonatal hippocampal lesion (model of schizophrenia) in the rat, the duration of this response is increased. We could assume that autism and schizophrenia may have responses and modulation pathways in common, which may be increasing the release of cortisol in some way. It has recently been reported that children diagnosed with ASD present an elevation of the stress hormones [53], particularly cortisol, which agrees with our results. On the other hand, there was a differential effect between male and female rats exposed prenatally to VPA for the duration of dorsal immobility (DI). In this response, only the male rats increased their time of immobility, an effect that was shown at the three ages studied, instead, there was no effect on female rats. As previously reported, DI and IC responses can be differentially affected. The stimuli that trigger these two kinds of immobility responses vary, due to the regions of the body that are involved. Although both are performed for protection, they are presented in different circumstances [42] [54] [55]. There is a connection between the trigeminal nucleus, the vestibular system and the immobility response [42] [56]. In addition, it has been found that in a model of autism, there is an alteration in the trigeminal nucleus [57], which suggests that the disturbance in this nucleus could modify the immobility responses [58]. Catalepsy was presented in male and female rats exposed prenatally to VPA, but not in control rats, although this effect decreased in male rats and was only significant on day 35 , in females the effect remained until adulthood. It is well known that catalepsy is closely related to disorders in dopaminergic systems. Indeed, dopamine antagonists are used to treat some symptoms, such as aggression and self-injury in ASD persons [59]. People with ASD may have catalepsy, being diagnosed generally during the adolescence (14 - 15 years old) [40] [60] [61], and remaining up to adulthood [62]. Therefore, it is relevant that male and female rats exposed prenatally to VPA have catalepsy, which makes it a good model of autism. There are studies that demonstrate a possible connection between attention-deficit/hyperactivity disorder (ADHD) and autism spectrum disorder (ASD) symptoms [63] [64] [65], however, until now this connection is unclear. In this model, we found that female rats prenatally exposed to VPA exhibited an increase in their locomotor activity [66], as well as in the time of stereotypy. Nevertheless, this was not obtained with male rats exposed to VPA prenatally. It is known that some people with autism [6] have stereotyped movements, and in 
this model, female rats had this alteration.

About analgesia, in both male and female rats exposed to VPA prenatally, the latency of withdrawal time of their tail is increased, although in female rats it only appears on day 35 and in males, this increase is maintained up to day 180. It has been reported that people who have autism have reduced pain sensitivity, however, there is a study that suggests that people with ASD do not have decreased sensitivity to pain, what happens is that they respond differently to the variety of circumstances that trigger the pain response [67]. In spite of the discrepancies about pain in people with ASD, in this model, female and male rats had a longer period of latency in the withdrawal of the tail to a painful stimulus.

Our results support the theory that mentions that the rate of prevalence of ASD between boys and girls is not 4 to 1 . That rate could be wrong because of the differences that boys and girls have during their development. Therefore, the alterations that they have are different, leading to a misdiagnosis [68]. It is also known that there are differences in multiple regions of the brain between boys and girls diagnosed with ASD. It has also been observed that there are differences in the connectivity of the white matter in the parietal and temporal regions [69]. This model in male and female rats can contribute to a better understanding of how children are affected by this disorder.

\section{Conclusion}

According to our results, we can determine that female and male rats exposed prenatally to VPA have different responses in this study, which can make it a good model to study and understand the differences that exist between boys and girls that suffer from ASD.

\section{Acknowledgements}

This study was partially supported by SIP 20170093; SIP 20170581. F de la C and M. F-C, are fellows of EDI, COFAA and SNI. L. G-R, J. L-M and G.F are SNI fellows. We thank to Instituto Politécnico Nacional.

Thanks to Professor Robert Simpson for editing the English language text.

\section{Conflict of Interest}

The authors declare that there is no duality of interest associated with this manuscript.

\section{References}

[1] Meador, K., Reynolds, M.W., Crean, S., Fahrbach, K. and Probst, C. (2008) Pregnancy Outcomes in Women with Epilepsy: A Systematic Review and Meta-Analysis of Published Pregnancy Registries and Cohorts. Epilepsy Research, 81, 1-13. https://doi.org/10.1016/j.eplepsyres.2008.04.022

[2] Adab, N., Kini, U., Vinten, J., Ayres, J., Baker, G., Clayton-Smith, J., Coyle, H., Fryer, A., Gorry, J., Gregg, J., Mawer, G., Nicolaides, P., Pickering, L., Tunnicliffe, L. and Chadwick, D.W. (2004) The Longer Term Outcome of Children Born to Moth- 
ers with Epilepsy. Journal of Neurology, Neurosurgery, and Psychiatry, 75, 1575-1583. https://doi.org/10.1136/jnnp.2003.029132

[3] Williams, G., King, J., Cunningham, M., Stephan, M., Kerr, B. and Hersh, J.H. (2001) Fetal Valproate Syndrome and Autism: Additional Evidence of an Association. Developmental Medicine \& Child Neurology, 43, 202-206. https://doi.org/10.1111/j.1469-8749.2001.tb00188.x

[4] Wagner, G.C., Reuhl, K.R., Cheh, M., McRae, P. and Halladay, A.K. (2006) A New Neurobehavioral Model of Autism in Mice: Pre and Postnatal Exposure to Sodium Valproate. Journal of Autism and Developmental Disorders, 36, 779-793. https://doi.org/10.1007/s10803-006-0117-y

[5] Christensen, J., Gronborg, T.K., Sorensen, M.J., Schendel, D., Parner, E.T., Pedersen, L.H. and Vestergaard, M. (2013) Prenatal Valproate Exposure and Risk of Autism Spectrum Disorders and Childhood Autism. JAMA, 309, 1696-1703.

https://doi.org/10.1001/jama.2013.2270

[6] American Psychiatric Association. (2013) Diagnostic and Statistical Manual of Mental Disorders. 5th Edition, American Psychiatric Association, Washington DC.

[7] Dufour-Rainfray, D., Vourc'h, P., Tourlet, S., Guilloteau, D., Chalon, S. and Andres, C.R. (2011) Fetal Exposure to Teratogens: Evidence of Genes Involved in Autism. Neuroscience \& Biobehavioral Reviews, 35, 1254-1265. https://doi.org/10.1016/j.neubiorev.2010.12.013

[8] Crawley, J.N. (2012) Translational Animal Models of Autism and Neurodevelopmental Disorders. Dialogues in Clinical Neuroscience, 14, 293-305.

[9] Hertz-Picciotto, I., Croen, L.A., Hansen, R., Jones, C.R., van de Water, J. and Pessah, N. (2006) The CHARGE Study: An Epidemiologic Investigation of Genetic and Environmental Factors Contributing Autism. Environmental Health Perspectives, 114, 1119-1125. https://doi.org/10.1289/ehp.8483

[10] Bugge, M., Bruun-Petersen, G. and Brondum-Nielsen, K. (2000) Disease Associated Balanced Chromosome Rearrangements: A Resource for Large Scale Genotype-Phenotype Delineation in Man. Journal of Medical Genetics, 37, 858-865. https://doi.org/10.1136/jmg.37.11.858

[11] Cook, E.H. and Scherer, S.W. (2008) Copy-Number Variation Associated with Neuropsychiatric Conditions. Nature, 455, 919-923. https://doi.org/10.1038/nature07458

[12] El-Fishawy, P. and State, M.W. (2010) The Genetics of Autism: Key Issues, Recent Findings and Clinical Implications. Psychiatric Clinics of North America, 33, 83-105.

[13] Wiggins, L., Baio, J. and Rice, C. (2006) Examination of the Time between First Evaluation and First Autism Spectrum Diagnosis in a Population-Based Sample. Journal of Developmental \& Behavioral Pediatrics, 27, S79-S87. https://doi.org/10.1097/00004703-200604002-00005

[14] Giarelli, E., Wiggins, L.D., Rice, C.E., Levy, S.E., Kirby, R.S., Pinto-Martin, J. and Mandell, D. (2010) Sex Differences in the Evaluation and Diagnosis of Autism Spectrum Disorders among Children. Disability and Health Journal, 3, 107-116.

[15] Wing, L. (1981) Sex Ratios in Early Childhood Autism and Related Conditions. Psychiatry Research, 5, 129-137.

[16] Volkmar, F.R., Szatmari, P. and Sparrow, S.S. (1993) Sex Differences in Pervasive Developmental Disorders. Journal of Autism and Developmental Disorders, 23, 579-591. https://doi.org/10.1007/BF01046103 
[17] Crider, A., Thakkar, R., Ahmed, A.O. and Pillai, A. (2014) Dysregulation of Estrogen Receptor Beta (ER $\beta$ ), Aromatase (CYP19A1), and ER Co-Activators in the Middle Frontal Gyrus of Autism Spectrum Disorder Subjects. Molecular Autism, 5, 46. https://doi.org/10.1186/2040-2392-5-46

[18] Malyshev, A.V., Abbasova, K.R., Averina, O.A., Solovieva, L.N., Gedzun, V.R., Gulyaev, M.V. and Dubynin, V.A. (2015) Fetal Valproate Síndrome as an Experimental Model of Autism. Physiology. Moscow University Biological Science Bulletin, 70, 110-114. https://doi.org/10.3103/S0096392515030074

[19] Rinaldi, T., Perrodin, C. and Markram, H. (2008) Hyper-Connectivity and Hyper-Plasticity in the Medial Prefrontal Cortex in the Valproic Acid Animal Model of Autism. Frontiers in Neural Circuits, 2, 4. https://doi.org/10.3389/neuro.04.004.2008

[20] Schumann, C.M. and Amaral, D.G. (2006) Stereological Analysis of Amygdala Neuron Number in Autism. Journal of Neuroscience, 26, 7674-7679. https://doi.org/10.1523/JNEUROSCI.1285-06.2006

[21] Markram, K., Rinaldi, T., Mendola, D.L., Sandi, C. and Markram, H. (2008) Abnormal Fear Conditioning and Amygdala Processing in an Animal Model of Autism. Neuropsychopharmacology, 33, 901-912. https://doi.org/10.1038/sj.npp.1301453

[22] Ritvo, E.R., Freeman, B.J., Scheibel, A.B., Duong, T., Robinson, H., Guthrie, D. and Ritvo, A. (1986) Lower Purkinje Cell Counts in the Cerebella of Four Autistic Subjects: Initial Findings of the UCLA-NSAC Autopsy Research Report. The American Journal of Psychiatry, 143, 862-866. https://doi.org/10.1176/ajp.143.7.862

[23] Ingram, J.L., Peckham, S.M., Tisdale, B. and Rodier, P.M. (2000) Prenatal Exposure of Rats to Valproic Acid Reproduces the Cerebellar Anomalies Associated with Autism. Neurotoxicology and Teratology, 22, 319-324.

[24] Hollander, E., Anagnotous, E., Chaplin, W., Esposito, K., Haznedar, M.M., Licalzi, E., Wasserman, S., Soorya, L. and Buchsbaum, M. (2005) Striatal Volume on Magnetic Resonance Imaging and Repetitive Behaviors in Autism. Biological Psychiatry, 58, 226-232.

[25] Zhang, M.M., Yu, K., Xiao, C. and Ruan, D.Y. (2003) Effects of Sodium Valproate on Synaptic Plasticity in the CA1 Region of Rat Hippocampus. Food and Chemical Toxicology, 411, 617-623.

[26] Schumann, C.M., Hamstra, J., Goodlin-Jones, B.L., Lotspeich, L.J., Kwon, H., Buonocore, M.H., Lammers, C.R., Reiss, A.L. and Amaral, D.G. (2004) The Amygdala Is Enlarged in Children But Not Adolescents with Autism; The Hippocampus Is Enlarged at All Ages. Journal of Neuroscience, 24, 6392-6401. https://doi.org/10.1523/JNEUROSCI.1297-04.2004

[27] Raymond, G.V., Bauman, M.L. and Kemper, T.L. (1996) Hippocampus in Autism: A Golgi Analysis. Acta Neuropathologica, 91, 117-119. https://doi.org/10.1007/s004010050401

[28] Miyazaki, K., Narita, N. and Narita, M. (2005) Maternal Administration of Thalidomide or Valproic Acid Causes Abnormal Serotonergic Neurons in the Offspring: Implication for Pathogenesis of Autism. International Journal of Developmental Neuroscience, 23, 287-297.

[29] Narita, N., Kato, M., Tazoe, M., Miyazaki, K., Narita, M. and Okado, N. (2002) Increased Monoamine Concentration in the Brain and Blood of Fetal Thalidomideand Valproic Acid-Exposed Rat: Putative Animal Models for Autism. Pediatric Research, 52, 576-579. 
[30] Chen, P.S., Peng, G.S., Li, G., Yang, S., Wu, X., Wang, C.C., Wilson, B., Lu, R.B., Gean, P.W., Chuang, D.M. and Hong, J.S. (2006) Valproate Protects Dopaminergic Neurons in Midbrain Neuron/Glia Cultures by Stimulating the Release of Neurotrophic Factors from Astrocytes. Molecular Psychiatry, 11, 1116-1125. https://doi.org/10.1038/sj.mp.4001893

[31] Rinaldi, T., Kulangara, K., Antoniello, K. and Markram, H. (2007) Elevated NMDA Receptor Levels and Enhanced Postsynaptic Long-Term Potentiation Induced by Prenatal Exposure to Valproic Acid. Proceedings of the National Academy of Sciences, 104, 13501-13506. https://doi.org/10.1073/pnas.0704391104

[32] Schneider, T., Ziolkowska, B., Gieryk, A., Tyminska, A. and Przewlocki, R. (2007) Prenatal Exposure to Valproic Acid Disturbs the Enkephalinergic System Functioning, Basal Hedonic Tone, and Emotional Responses in an Animal Model of Autism. Psychopharmacology, 193, 547-555. https://doi.org/10.1007/s00213-007-0795-y

[33] Kerr, D.M., Downey, L., Conboy, M., Finn D.P. and Roche, M. (2013) Alterations in the Endocannabinoid System in the Rat Valproic Acid Model of Autism. Behavioural Brain Research, 249, 124-132.

[34] Schneider, T. and Przewłocki, R. (2005) Behavioral Alterations in Rats Prenatally to Valproic Acid: Animal Model of Autism Neuropsychopharmacology, 30, 80-89. https://doi.org/10.1038/sj.npp.1300518

[35] Schneider, T., Labuz, D. and Przewlocki, R. (2001) Nociceptive Changes in Rats after Prenatal Exposure to Valproic Acid. Polish Journal of Pharmacology, 53, 531-534.

[36] Schneider, T., Turczak, J. and Przewlocki, R. (2006) Environmental Enrichment Reverses Behavioral Alterations in Rats Prenatally Exposed to Valproic Acid: Issues for a Therapy Approach in Autism. Neuropsychopharmacology, 31, 36-46.

[37] Rapin, I. and Tuchman, R.F. (2008) Autism; Definition, Neurobiology, Screening, Diagnisis. Pediatric Clinics of North America, 155, 1129-1146.

[38] Dhossche, D.M. and Bouman, N.H. (1997) Catatonia in Children and Adolescents. Journal of the American Academy of Child and Adolescent Psychiatry, 36, 870-871. https://doi.org/10.1097/00004583-199707000-00007

[39] Dhossche, D. (1998) Brief Report: Catatonia in Autistic Disorders. Journal of Autism and Developmental Disorders, 28, 329-331. https://doi.org/10.1023/A:1026064720287

[40] Wing, L. and Shah, A. (2000) Catatonia in Autistic Spectrum Disorders. The British Journal of Psychiatry, 176, 357-362. https://doi.org/10.1192/bjp.176.4.357

[41] Hare, D.J. and Malone, C. (2004) Catatonia an Autistic Spectrum Disorders. Autism, 8, 183-195. https://doi.org/10.1177/1362361304042722

[42] De la Cruz, F., Junquera, J. and Russek, M. (1987) Ontogeny of Immobility Reactions Elicited by Clamping, Bandaging and Maternal Transport in Rats. Experimental Neurology, 97, 315-326.

[43] Flores, G., Silva-Gómez, A.B., Barbeau, D., Srivastava, L.K., Zamudio, S. and De la Cruz-López, F. (2005) Effect of Excitotoxic Lesions of the Neonatal Ventral Hippocampus on the Immobility Response in Rats. Life Sciences, 76, 2339-2348.

[44] De La Cruz, F. and Uriostegui, T. (1996) The Differential Haloperidol Effect on the Immobility Response Elicited by Clamping, Grasping, Bandaging and Inversion in Guinea Pig, Hamster and Rat. Behavioural Brain Research, 78, 195-199.

[45] Jaramillo-Loranca, B.E., Garcés-Ramírez, L., Munguía Rosales, A.A., Luna Ramírez, 
C., Vargas Hernández, G., Morales-Dionisio, O., González-Elizalde, K., Flores, G., Zamudio, S. and De La Cruz-López, F. (2015) The Sigma Agonist 1,3-di-o-tolyl-guanidine Reduces the Morphological and Behavioral Changes Induced by Neonatal Ventral Hippocampus Lesion in Rats. Synapse, 69, 213-225. https://doi.org/10.1002/syn.21811

[46] Zamudio, S.R., Quevedo-Corona, L., Garcés, L. and De La Cruz, F. (2009) The Effects of Acute Stress and Acute Corticosterone Administration on the Immobility Response in Rats. Brain Research Bulletin, 80, 331-336.

[47] Mabunga, D.F., Gonzales, E.L., Kim, J.W., Kim, K.C. and Shin, C.Y. (2015) Exploring the Validity of Valproic Acid Animal Model of Autism. The Journal of Experimental Biology, 24, 285-300.

[48] Meyer, M.E., Smith, R.L. and Van Hartesveldt, C. (1984) Haloperidol Differentially Potentiates Tonic Immobility, the Dorsal Immobility Response, and Catalepsy in the Developing Rat. Developmental Psychobiology, 17, 383-389.

https://doi.org/10.1002/dev.420170405

[49] Jaramillo-Loranca, B.E., De la Cruz, F., Vargas, G., Morales-Dionisio, O., Flores, G., Zamudio, S.R. and Garcés-Ramírez, L. (2014) Differential Effect on Two Immobility Responses by Chronic Administration of 1,3-di-o-Tolyl-Guanidine (Sigma Receptor Agonist) in Rats with Neonatal Ventral Hippocampal Lesion. PP, 5, 681-690. https://doi.org/10.4236/pp.2014.57078

[50] Teitelbaum, P., Teitelbaum, O., Nye, J., Fryman, J. and Maurer, R.G. (1998) Movement Analysis in Infancy May Be Useful for Early Diagnosis of Autism. Proceedings of the National Academy of Sciences, 10, 13982-13987. https://doi.org/10.1073/pnas.95.23.13982

[51] De la Cruz, F., Russek, M. and Junquera, J. (1990) Ontogeny of the Endorphinergic and Dopaminergic Modulation on the Immobility Reflex Elicited by Clamping in Rats. International Journal of Psychophysiology, 9, 171-177.

[52] Klemm, W.R. (2001) Behavioral Arrest: In Search of the Neural Control System. Progress in Neurobiology, 65, 453-471.

[53] Ogawa, S., Lee, Y.A., Yamaguchi, Y., Shibata, Y. and Goto, Y. (2017) Associations of Acute and Chronic Stress Hormones with Cognitive Functions in Autism Spectrum Disorder. Neuroscience, 343, 229-239.

[54] Gallup, G.G. (1974) Animal Hypnosis: Factual Status of a Fictional Concept. Psychological Bulletin, 81, 836-853. https://doi.org/10.1037/h0037227

[55] Fluck, E., Hogg, S., Jones, R.B., Bourne, R. and File, S.E. (1997) Changes in Tonic Immobility and the GABA-Benzodiazepine System in Response to Handling in the Chick. Pharmacology Biochemistry and Behavior, 58, 269-274.

[56] Brodal, A. and Saugstad, L.F. (1965) Retrograde Cellular Changes in the Mesencephalic Trigeminal Nucleus in the Cat Following Cerebellar Lesions. Acta Morphologica Neerlando-Scandinavica, 6, 147-159.

[57] Rodier, P.M., Ingram, J.L., Tisdale, B., Nelson, S. and Romano, J. (1996) Embryological Origin for Autism: Developmental Anomalies of the Cranial Nerve Motor Nuclei. Journal of Comparative Neurology, 370, 247-261. https://doi.org/10.1002/(SICI)1096-9861(19960624)370:2<247::AID-CNE8>3.0.CO; $2-2$

[58] Brewster, J. and Leon, M. (1980) Facilitation of Maternal Transport by Norway Rat Pups. Journal of Comparative and Physiological Psychology, 94, 80-88. https://doi.org/10.1037/h0077645 
[59] Hellings, J.A., Arnold, L.E. and Han, J.C. (2017) Dopamine Antagonists for Treatment Resistance in Autism Spectrum Disorders: Review and Focus on BDNF Stimulators Loxapine and Amitriptyline. Expert Opinion on Pharmacotherapy, 18, 581-588. https://doi.org/10.1080/14656566.2017.1308483

[60] Realmuto, G.M. and August, G.J. (1991) Catatonia in Autistic Disorder: A Form of Comorbidity or Variable Expression. Journal of Autism and Developmental Disorders, 21, 517-528. https://doi.org/10.1007/BF02206874

[61] Wing, L. and Shah, A. (2006) A Systematic Examination of Catatonia-Like Clinical Pictures in Autism Spectrum Disorders. International Review of Neurobiology, 72, 21-39.

[62] Gillberg, C. and Billstedt, E. (2000) Autism and Asperger Syndrome: Coexistence with Other Clinical Disorders. Acta Psychiatrica Scandinavica, 102, 321-330. https://doi.org/10.1034/j.1600-0447.2000.102005321.x

[63] Nijmeijer, J.S., Hoekstra, P.J., Minderaa, R.B., Buitelaar, J.K., Altink, M.E., Buschgens, C.J.M., Fliers, E.A., Rommelse, N.N., Sergeant, J.A. and Hartman, C.A. (2008) PDD Symptoms in ADHD, an Independent Familial Trait? Journal of Abnormal Child Psychology, 37, 443-453. https://doi.org/10.1007/s10802-008-9282-0

[64] Reiersen, A.M., Constantino, J.N., Grimmer, M., Martin, N.G. and Todd, R.D. (2008) Evidence for Shared Genetic Influences on Self-Reported ADHD and Autistic Symptoms in Young Adult Australian Twins. Twin Research and Human Genetics, 11, 579-585. https://doi.org/10.1375/twin.11.6.579

[65] Mulligan, A., Anney, R.J.L., O’Regan, M., Chen, W., Butler, L., Fitzgerald, M., Buitelaar, J., Steinhausen, H.C., Rothenberger, A., Minderaa, R., Nijmeijer, J., Hoekstra, P.J., Oades, R.D., Roeyers, H., Buschgens, C., Christiansen, H., Franke, B., Gabriels, I., Hartman, C., Kuntsi, J., Marco, R., Meidad, S., Mueller, U., Psychogiou, L., Rommelse, N., Thompson, M., Uebel, H., Banaschewski, T., Ebstein, R., Eisenberg, J., Manor, I., Miranda, A., Mulas, F., Sergeant, J., Sonuga-Barke, E., Asherson, P., Faraone, S.V. and Gill, M. (2009) Autism Symptoms in Attention-Deficit/Hyperactivity Disorder: A Familial Trait Which Correlates with Conduct, Oppositional Defiant, Language and Motor Disorders. Journal of Autism and Developmental Disorders, 39, 197-209. https://doi.org/10.1007/s10803-008-0621-3

[66] Schneider, T., Roman, A., Basta-Kaim, A., Kubera, M., Budziszewska, B., Schneider, K. and Przewłocki, R. (2008) Gender-Specific Behavioral and Immunological Alterations in an Animal Model of Autism Induced by Prenatal Exposure to Valproic acid. Psychoneuroendocrinology, 33, 728-740.

[67] Tordjman, S., Anderson, G.M., Botbol, M., Brailly-Tabard, S., Perez-Diaz, F., Graignic, R., Carlier, M., Schmit, G., Rolland, A.C., Bonnot, O., Trabado, S., Roubertoux, P. and Bronsard, G. (2009) Pain Reactivity and Plasma Beta-Endorphin in Children and Adolescents with Autistic Disorder. PLOS ONE, 4, e5289.

[68] Duvekot, J., van der Ende, J., Verhulst, F.C., Slappendel, G., van Daalen, E., Maras, A. and Greaves-Lord, K. (2017) Factors Influencing the Probability of a Diagnosis of Autism Spectrum Disorder in Girls versus Boys. Autism, 21, 646-658. https://doi.org/10.1177/1362361316672178

[69] Irimia, A., Torgerson, C.M., Jacokes, Z.J. and Van Horn, J.D. (2017) The Connectomes of Males and Females with Autism Spectrum Disorder Have Significantly Different White Matter Connectivity Densities. Scientific Reports, 7, Article No. 46401. https://doi.org/10.1038/srep46401 